William B. McGregor*

\title{
Reported speech as a dedicated grammatical domain - and why defenestration should not be thrown out the window
}

https://doi.org/10.1515/lingty-2019-0010

\section{Introduction}

Perhaps the most significant contribution of Spronck and Nikitina (2019) (henceforth $\mathrm{S} \& \mathrm{~N}$ ) is that it proposes, albeit perhaps not for the first time, criteria that must be met by a construction in any given language in order to count as a reported speech construction. This attempt at a language independent definition of reported speech constructions paves the way for motivated cross-linguistic comparison, ensuring that what are compared in the languages are indeed comparables.

To their credit, S\&N address the presupposition that such constructions exist. They provide reason to believe that at least some expressions reporting speech represent emically genuine phenomena within the language in which they occur. That is, they are constructions - grammatical signs, pairings of form and meaning (as per e.g. construction grammar - e.g. Goldberg 1995: 4). Contra the claims of some, reported speech is not a mere 'multimodal' phenomenon, unsignalled by grammatical structure, and external to the grammar.

Equipped with a definition of the type provided by S\&N we can address typological questions such as whether or not every language shows a reported speech construction (as indicated in the paper, there is no attestation of a language without such a construction), and what range of variation might exist within them both formally and functionally. The definition provided in $\$ 3.1$ (numbered (31)) identifies three meaning components that must be satisfied by constructions in any given language to count as a reported speech construction. Formal properties of the construction are not specified as such in (31). However, the previous section, §2, identifies one in the course of an overview of the grammatical properties of reported speech. Thus, to count as a reported speech construction the structure must involve two separate morphosyntactic units, an M (matrix) and an R (reported) in some syntactic relation to one another.

\footnotetext{
*Corresponding author: William B. McGregor ['wıtjm,bi:mə'gıદgə], Department of Linguistics, Cognitive Science and Semiotics, The School of Communication and Culture, Aarhus University, Jens Chr. Skous Vej 2, Office 1485-617, DK-8000, Aarhus C, Denmark, E-mail: linwmg@cc.au.dk
} 
This type of approach instantiates the typological methodology McGregor (1997: 15-16), Rijkhoff (2016) and LaPolla (2016) advocate, that is, that the cross-language comparanda should be emic phenomena in the separate languages. Of course, these are language particular categories, "descriptive categories" in the terminology of Haspelmath (2010, 2016). But being language particular does not mean that they are inherently non-comparable. They may be compared on both formal and functional grounds in terms of likeness - as Rijkhoff (2016: 333) puts it, "formal and semantic criteria are employed to arrive at a morphosyntactic category whose members are sufficiently similar in terms of function, form and meaning" (see also McGregor 1997: 15-16). Reported speech thus turns out to be more than a mere comparative category of the typologist in the sense of Haspelmath (2010, 2016).

\section{The proposed definition of reported speech}

Whilst I find the approach advocated by S\&N a necessary step in the right direction, there remain a number of points that are in need of further development, and I am not convinced by all of the details of their proposals. We begin with the formal aspect of the definition of reported speech proposed by the authors (§2.1), then turn to the semantic aspect (§2.2). Finally, in Section 2.3 we combine the two aspects in a discussion of defenestration.

\subsection{Formal criteria}

As just mentioned, to count as a reported speech construction the construction must involve $\mathrm{M}$ and $\mathrm{R}$ components ( $\mathrm{S} \& \mathrm{~N}$ : §2.1). One obvious point requiring further investigation concerns the grammatical relation between the $M$ and $R$ units. As the authors say ( $\$ 2.1$ ), and as has been observed by many others, there is reason to believe that the relation is neither subordination nor coordination: it shows properties distinguishing it from these dependency relations. I would add that the relation cannot be embedding either (see McGregor 1994, 1997: 56). This leaves unanswered, indeed unaddressed, the question: what is the syntactic relation between $M$ and $R$ ? I have suggested that it is framing, a relation that is based on analogy with framing of pictorial representations and is somewhat similar to scoping - see McGregor (1994, 1997: 251-258). This, I have observed, provides an explanation for some of the grammatical features of reported speech, including the variety of possible choices of deictic centre for shifting categories in the $\mathrm{R}$. 
In the ideal case both $\mathrm{M}$ and $\mathrm{R}$ will be clauses, as in Spronck and Nikitina's example (1), John said: “Look, there is marmalade here!". Things are not always so clear-cut, as the authors acknowledge. For instance, in a number of languages - including Megeb Dargwa (cited in the paper, example (7) in S\&N) - we find hearsay markers. As I understand them, S\&N would treat these as instances of an M-unit, and would see clauses marked by a hearsay marker as instances of reported speech. However, the hearsay marker does not specify anything more than that the clause it marks is asserted on the basis of what the speaker has heard or been told in unspecified circumstances. What is going on seems to be very much like what is going on in English with adverbials such as allegedly, apparently, and the like, and the (e) line of Nyulnyul example (8), where the clause of speech does not act as an M (as S\&N rightly observe). It does not frame the erstwhile $\mathrm{R}$ clause, but merely specifies the evidential basis on which it is asserted. It is not at all clear to me that evidential-marked clauses like (7), any more than the clause of liking in (8)(e), are demonstrations rather than descriptions (see further below). What Ms might be other than clauses demands further attention. (By contrast, there appear to be few restrictions on $\mathrm{R}$, beyond perhaps that it must normally be utterable, and so a free linguistic unit.)

\subsection{Semantic criteria}

Turning now to the semantic aspects of the proposed definition of reported speech, numbered (31) in S\&N propose three semantic components that must be present for a construction to count as an instance of reported speech: demonstratedness, evidentiality and epistemic modality. Whilst it seems reasonable to insist on the demonstrated status (in the sense of Clark \& Gerrig 1990) of one component of the reported speech construction - of the R unit - I am not so convinced of the necessity of the other two components.

First, the evidential meaning seems to come for free, a consequence of the presence of the two component units, the $M$ and $R$, in which $M$ indexes a speech situation other than the present one of the utterance.

Second, the requirement that there be a feature of epistemic evaluation of the $\mathrm{R}$ unit - modulation of commitment to the truth value - seems far too strong, and excludes many instances that the authors would presumably include under the umbrella of reported speech. Thus cases where $\mathrm{R}$ does not express a proposition - e.g. imperatives in languages like English, and interjection clauses such as aha, hi, no way, and the like - must be excluded. Weakening of the requirement to include deontic modulation would save things for imperative Rs, but not for minor clause Rs. 
It is not obvious to me how Spronck and Nikitina's modality requirement, (31)(c), would be best revised to admit these counterexamples. This is perhaps where the notion of distancing - as suggested by Güldemann (2008: 6) and others - could be invoked. As S\&N observe, there are some difficulties with this notion, e.g. when applied to self-quotes. However, I am not convinced that these are insurmountable, and that the notion of distancing cannot be refined to deal with these apparent counterexamples (see also below on explicit performatives).

S\&N: $\$ 3.2$ discuss some issues in the application of their definition of reported speech by examining some borderline cases. I would like to follow up on the discussion of just two of them.

First is the treatment of belief complements, as in S\&N's example (32) He believes that there is no tooth fairy. The authors claim two possible interpretations of such examples, one in which the complement describes a belief, the other in which it demonstrates the belief. The first interpretation I cannot understand as formulated: there is no tooth fairy cannot describe a belief. It can surely only describe a real or imaginary world situation, and as a consequence express a proposition that could be true or false - and hence believed or not. The belief itself can surely only be demonstrated, provided with a linguistic representation of its (possible) shape. The two imputed interpretations thus depend on whether there is no tooth fairy describes a situation - not a thought - or demonstrates the shape of the thought.

When there is no tooth fairy demonstrates a thought, the interpretation of (32) is clear. Not so for the other reading, and S\&N do not clarify the meaning of the complement construction in the description alternative. I presume that in this circumstance the believe-clause is interpreted as providing epistemic modalisation of the that-clause. But this interpretation is difficult to implement in (32). It would seem most natural when the believer is either generic (as in e.g. One might believe (that) there is no tooth fairy) or a participant in the current speech situation (as in I believe (that) there is no tooth fairy, I don't believe (that) there is a tooth fairy and So you don't believe (that) there is a tooth fairy!). The broader relevance of this point concerns whether in a given language both interpretations are available, and correspond to different grammatical structures, propositional scoping and thought framing.

The second matter I would take issue with is the treatment of explicit performatives such as e.g. I am ordering you to go, I am asking you to please quieten down, and perhaps also examples of the type I'm thinking "Indeed I'll go tomorrow" where the R unit is explicitly labelled as a thought. By the definition provided by S\&N these - and other phenomena of self-now-quotation - must be excluded from reported speech since there is no other moment than the current speech moment in which the reported utterance occurred, in conflict with (31) 
(b). But is the exclusion of these phenomena from reported speech motivated? If I ordered you to go is reported speech, why not I am ordering you to go? And why should apparently comparable examples like I am saying I live here (one component of S\&N's (18)) and the Nanti example (1) be admitted as reported speech?
noka hanta no=n-tim-e
Kuriha-ku
1.QUOT there 1S=IRREAL-live-IRREAL Peach.Palm.Creek-LOC
'I say, "I will live there at Peach Palm Creek."' ((19) in S\&N, citing Michael 2010: 5; abbreviations as in S\&N)

S\&N and Michael (2010) both use self-quotes such as (1) to argue against the view that reported speech codes a distancing sense: the effect of (1) is to strongly assert the R, marking it as a "sincere intention". I do not believe that this actually constitutes an argument against distancing, only an argument against one narrow interpretation of distancing - where the assertion is shifted to the domain of questionability. But it is equally plausible to distance oneself from a proposition by putting it as it were in the beyond-question domain. Greater than usual commitment to a proposition, and its assignment to the domain of beyond question, is as much distancing as is less than usual commitment, and questioning it. As already observed, rather than reject distancing as an inherent component of the meaning of reported speech constructions, we need to examine more carefully what might be meant by the term.

Explicit performatives, it seems to me, can plausibly be understood as one of many means available to speakers to distance themselves from their current utterance. Thus examples such as I am telling you that he is in for a surprise show the commitment-enhancement type of distancing. Others, such as e.g. I'm ordering you to leave, I'm asking you to take the rubbish out, I'm requesting that you observe the usual rules of behaviour, and the like, serve as indirect means of performing speech acts of ordering, asking and requesting by use of clauses in declarative mood. Distancing in this way would seem to serve to make the utterance more polite.

As S\&N observe, the evidential component is not present in explicit performatives. ${ }^{1}$ But if the evidential meaning is not, as I have suggested, coded, but inferred when the present and reported speech situations are distinct, this does not argue against explicit performatives as instances of reported speech. The presence of the evidential component of meaning is dependent on whether or not the reported speech or thought situation is identical with the current one.

1 An intriguing possibility is that auto-evidentiality is involved in explicit performatives, giving a proximal deictic value to match the otherwise distal deixis of evidentiality. 
This opens up the possibility that the evidential meaning of ordinary reported speech is defeasible, which I believe is the case. Moreover, if the modal meaning is expanded to include deontic (and perhaps other types of) modality, the third component of S\&N's definition is met, at least as a conventional implicature.

\subsection{Defenestration}

An additional problem is raised by the formal component of the definition of reported speech, namely the phenomenon provided with the rather evocative label defenestration: the situation - recurrent in many languages - in which an $\mathrm{M}$ element appears to be completely lacking, and only an R element is evident. As I understand it, S\&N's proposal is that in defenestration the M element is ellipsed, and thus that in the typical reported speech construction the M element is optional in the sense of McGregor (2013). ${ }^{2}$ If optionality is indeed involved, a raft of interesting language-particular questions arises relating to the circumstances under which the optionality of $M$ is permissible, and whether the presence and/or absence of the $\mathrm{M}$ codes or implicates any meanings of the type identified by McGregor (2013) - see Vandelanotte (forthcoming) for an example. For the typologist there are questions concerning the comparability of the circumstances for ellipsis and of the meanings expressed.

Backtracking somewhat, the term defenestration was coined by Spronck (2015: 15) in "a playful allusion to insubordination (the main clause usage of formally subordinate clauses, Evans 2007)”. This is fine, but I always wonder how far to push things in analogical thinking, whether an analogy can give fresh insights if pushed further than its original conceptual motivation. In this instance I believe that the analogy bears pushing further than S\&N attempt.

The term insubordination refers to the situation in which an apparently subordinate (bound) clause is used conventionally as a main (free) clause (see further Evans \& Honoré 2016a; Evans \& Watanabe 2016b). This is illustrated by (2).

\section{(2) If you could please tidy your room}

Two features of insubordination are germane. First, cross-linguistically it appears to express a range of modal or interactive types of meaning (see Evans 2007, 2009; Evans \& Watanabe 2016b; Verstraete et al. 2012; McGregor 2017). Thus English if-conditional insubordination as in (2) is often used to

2 This implication is not in fact warranted according to McGregor (2013): ellipsis and optionality are distinct, though overlapping phenomena. 
enhance the politeness of a request. Second, the idea that ellipsis of a putative main clause is always involved has been objected to by a number of investigators (e.g. Mithun 2008: 106-108; Heine et al. 2016: 59; Cristofaro 2016; McGregor 2017: 206).

Can we identify anything comparable in defenestration - that is, frameless reported speech expressions in which a modal meaning is conveyed, and ellipsis is not involved? The type of phenomena discussed by S\&N under defenestration do not satisfy these conditions: only modal meaning predicted by the reported nature of the construction seems to be involved, and ellipsis can be reasonably invoked. But consider the notice from a toilet in a railway carriage in Scotland shown in Figure 1, which seems to me to fit the bill for an instance of defenestration that does not involve ellipsis, and clearly expresses a special modal slant on the message content.

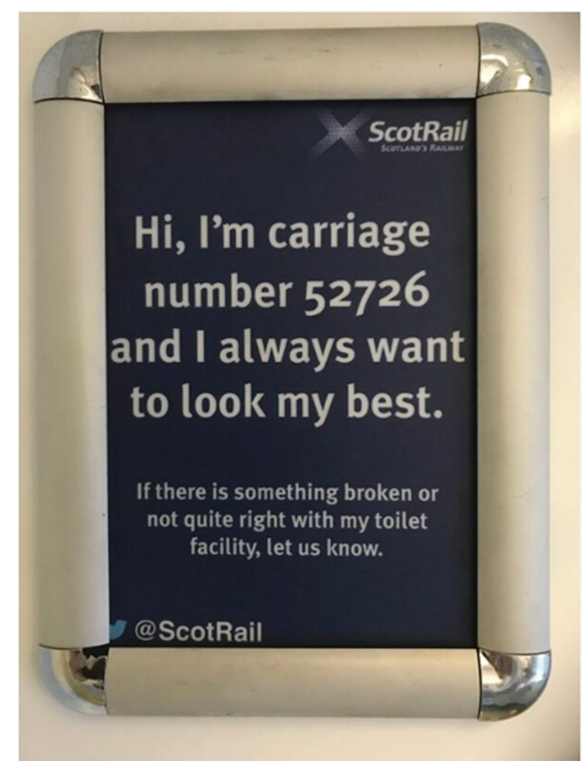

Figure 1: Photograph of a notice in the toilet of a carriage in a ScotRail train (author's photograph, 2018).

The two full sentences clearly show the hallmarks of an R element: the pronominal categories are represented from a centre in which the first person, the speaker, is the railway carriage and not the acknowledged and obvious source of the notice, ScotRail, identified in the top righthand corner. Indeed, I'm 
carriage number 52,726 serves to identify the putative speaker. ${ }^{3}$ There is no $\mathrm{M}$ element whatever, so presumably this is a candidate for defenestration. However, it is not clear that an M clause has been ellipsed or is optional.

First, for an ellipsis or optionality analysis to be viable there should be a definite meaning or referent expressed by a linguistic unit that is missing from the expression, that can be filled in from the linguistic or non-linguistic context or general knowledge. But this is not the case. All we can say is that it must be a possible M clause, e.g. Carriage 52,726 says/is telling you/notifies you/wants to inform you, among a range of others.

Second, Figure 1 purports to be a notice authored by the carriage, directed to the traveller: it is presented as though directly said by the carriage, and not an utterance of the carriage reported by ScotRail. To frame it would undermine this effect. The framing is inferred by the viewer, who knows that carriages cannot produce notices. Choice of this mode of expression modalises a message that might be expressed more neutrally by something like We like our carriages to look their best. If there is something broken or not quite right with the toilet facility of this carriage, let us know. The message is carried more intimately and personally by the fiction that it is by the carriage. The carriage is in effect used as a mouthpiece for ScotRail. Put in another way, the two sentences are in formal terms demonstrations, but at the same time are used descriptively (by the carriage, by implication), to directly portray some world of experience, rather than to enact the putative words of the railway carriage. Fascinatingly, in the final clause the notice slips seamlessly into pure descriptive semiosis, with no demonstrational component. The us must be ScotRail, and can hardly include the previous speaker, the carriage. In effect what is inherently a demonstration is used non-demonstratively, and "seriously" (contra Clark \& Gerrig 1990). This gives us a parallel with the proposals for the analysis of insubordination suggested in McGregor (2017): that insubordination is the use of a particular grammatical phenomenon as though something else.

I have observed a number of notices that, like the ScotRail sign, represent utterances of inanimates, including on rubbish trucks in Denmark; Wales (2013) and Pascual (2014: 4) give a number of examples, including in Dutch and AngloSaxon (Old English). I also recently observed religious billboards in the UK, in which an unspecified religious personage speaks to passer-bys using God as a mouthpiece. What seems to be crucial to these signs is that an utterance that can only be

3 Speaker identification in the shape of an identifying/equational clause like I'm carriage number 52,726 early in the $\mathrm{R}$ unit is an additional means of signalling reported speech status beyond the range of means identified in S\&N. However, it is by no means obligatory in notices of this type, as in the stickers on library books of my childhood, Please wash your hands before reading me. 
understood as a representation of what someone or something other than the sign author is represented as though it is directly from that someone or something as author.

The phenomenon is not peculiar to signage, and examples can also be found in spoken language. Consider for instance (3), spoken by a woman on a walking track in the UK. I was sitting with my wife, who was prominently holding an iPhone, beside the track eating lunch when the woman's dog came up to us, looking and sniffing at my backpack. We instantly understood this to be the imputed words or thoughts of the dog, and consistent with this the clause was produced on a somewhat marked intonation contour, employing a higher register than expected. (It is inconceivable that anyone would ask a stranger to take a photograph of them in this interactive context with an utterance like (3).)

\section{(3) Take a picture of me}

Quite obviously this was an attempt at humour - everyone laughed - aimed at defusing a situation of potential conflict and ultimately requesting that the dog be excused for its somewhat inappropriate, perhaps menacing, social behaviour. As in the other example discussed, the speaker employs something else as a mouthpiece for their own words, but putting them in a manner appropriate to that other thing as speaker. Again, there is no ellipsed or optional M clause: it is impossible to pin down the identity of the putative $\mathrm{M}$ clause. Moreover, employment of an explicit $\mathrm{M}$ clause would undermine the effect.

There is another environment in which something similar goes on, and another's utterance is incorporated into one's own without an explicit M unit, while the status of the utterance as a demonstration is indicated in some way. Here, in sharp contrast with examples such as the ScotRail notice discussed above, the shift between the two different semiotic modes is not seamless. This phenomenon - illustrated by example (4) - is not uncommon in academic writing and journalism. Clearly there is no $\mathrm{M}$ unit as such, and the addition of such an element (... which Halliday says “...") invokes the - in this case - undesired implicature that there is something questionable about the claim. (The alternative ... which, as Halliday says, “...” gets around this but then the clause of speech becomes parenthetical, and arguably not an M unit.)

(4) The definition of Theme as given by Halliday (1985a: 39) is that it is the element which 'serves as the starting-point for the message: it is what the clause is going to be about'. (Eggins 1994: 275, cited in McGregor 1997: 267) 
Adopting the words of another, and maintaining indication of their status as a demonstration, generally serves authorising and aligning functions in academic and journalistic discourse, strengthening the assertions of the author by putting them (partly) in the words of another, typically authority figure.

The same phenomenon can also be observed in everyday contexts. Consider (5), from an interaction between a mother and young child - see Pascual $(2014: 6$, 11) for more examples.

\section{(5) You don't have to have bread that "I hate." (cited in McGregor 1997: 267)}

Here again the status of the final two words as a demonstration was obvious from the marked prosody on which the utterance was produced. Furthermore the first person of the quoted piece was the addressee of the full sentence, not the speaker, palpable in the interactive context where the addressee had just expressed his dislike for the item of food. Contrasting (5) with the more straightforward "You don't have to eat bread that you hate" the meaning of the speaker's chosen construction becomes clear: she is providing an evidential basis for her claim about the child's internal thoughts and emotions and simultaneously showing alignment with the child by reusing his words. The mother could have added a framing clause of speech, but to do so would have been problematic on two grounds. First, if it had been framed as a direct quote, You don't have to have bread that you say "I hate", this would have been confusing in that it more naturally yields an interpretation as indirect speech, with the $I$ the mother. This is a context for "second person magnetism" (S\&N: fn.11), and the most natural expression would be You don't have to have bread that you say you hate. Both of these modes of expression with an $M$ clause are problematic because they invoke an epistemic modalisation of doubt, in conflict with the very point of employing the demonstrative semiotic. In the case of (4) and (5) the above arguments against ellipsis and optionality perhaps do not work. However, it seems that there is a genuine meaning contrast between the fenestrated and the defenestrated examples that could be used to argue their status as different grammatical signs or constructions. This however is beyond the scope of the present commentary.

To sum up this somewhat lengthy discussion, it seems to me that the term defenestration would be better restricted to unframed quotes of the type just discussed, in which a demonstration is used as though it were not a demonstration. Put in other terminology, a citation is used as though an instance of language usage - a mention is not merely mentioned but actually used. It is not that the distinction between mention and use is blurred (blurring of the distinction is well known): indeed, as discussed above the status of the words as 
citations/demonstrations is made perfectly clear by internal devices such as pronoun choice, presence of speaker-identifying clauses, prosody (in speech) and quote marks (in writing). Without such markers the words would lose their demonstrative character. They would be interpreted as simple descriptions, and could serve just one semiotic function, not both.

To the extent that reported speech serves a distancing function, defenestration (in the present sense) appears to serve a proximation function, expressing immediacy, alignment and/or intimacy. (Admittedly, as in the case of distancing, proximation needs further research.) It is these phenomena that are most like insubordination. Those more mundane instances in which a framing clause is simply ellipsed don't, in my view warrant their own label - they are simply cases of ellipsed Ms: deframed or frameless, and worthy of defenestration.

\section{Conclusion}

A good paper suggests new directions of research, raises novel questions. It seems to me that S\&N does this. In particular the analogical foundation of defenestration on insubordination raises a raft of intriguing possibilities that I have only hinted at here. Indeed, I suspect that defenestration might provide fresh insights into a number of other phenomena in language, including triadic communication of some West African languages (Ameka 2004). I disagree with a number of the authors' analyses and interpretations, but believe that overall they are on the right track. Most fundamentally, what we need in linguistic typology and description is an explicit set of criteria for classifying constructions as reported speech constructions. I am not convinced that S\&N have picked out the right criteria, either formally (where I suggest that in addition to the units $\mathrm{M}$ and $\mathrm{R}$ we need the specific grammatical relation of framing) or in relation to meaning (where I believe there is overkill in their proposals).

Acknowledgements: I am grateful to Jan Rijkhoff for discussions on themes treated in this note, and to Jean-Christophe Verstraete, Lieven Vandelanotte, An Van linden, Stef Spronk and Tatiana Nikitina for useful comments on an earlier draft.

\section{References}

Ameka, Felix K. 2004. Grammar and cultural practices: The grammaticalization of triadic communication in West African languages. Journal of West African Languages 30(2). 5-28. 
Clark, Herbert H. \& Richard J. Gerrig. 1990. Quotations as demonstrations. Language 66. 764-805.

Cristofaro, Sonia. 2016. Routes to insubordination: A cross-linguistic perspective. In Nicholas Evans \& Honoré Watanabe (eds.), Insubordination, 393-422. Amsterdam and Philadelphia: John Benjamins.

Eggins, Suzanne. 1994. An introduction to systemic functional linguistics. London: Pinter. Evans, Nicholas. 2007. Insubordination and its uses. In Irina Nikolaeva (ed.), Finiteness: Theoretical and empirical foundations, 366-431. Oxford: Oxford University Press.

Evans, Nicholas. 2009. Insubordination and the grammaticalisation of interactive presuppositions. Lecture given at the conference Methodologies in determining morphosyntactic change, Osaka, March 2009.

Evans, Nicholas \& Watanabe. Honoré (eds.). 2016a. Insubordination. (Typological Studies in Language, 115.). Amsterdam and Philadelphia: John Benjamins.

Evans, Nicholas \& Honoré Watanabe. 2016b. The dynamics of insubordination: An overview. In Nicholas Evans \& Honoré Watanabe (eds.), Insubordination, 1-37. Amsterdam and Philadelphia: John Benjamins.

Goldberg, Adele E. 1995. Constructions: A construction grammar approach to argument structure. Chicago and London: University of Chicago Press.

Güldemann, Tom. 2008. Quotative indexes in African languages: A synchronic and diachronic survey. Berlin and New York: Mouton de Gruyter.

Haspelmath, Martin. 2010. Comparative concepts and descriptive categories in crosslinguistic studies. Language 86(3). 663-687.

Haspelmath, Martin. 2016. The challenge of making language description and comparison mutually beneficial. Linguistic Typology 20(2). 299-303.

Heine, Bernd, Gunther Kaltenböck \& Tania Kuteva. 2016. On insubordination and cooptation. In Nicholas Evans \& Honoré Watanabe (eds.), Insubordination, 39-63. Amsterdam and Philadelphia: John Benjamins.

LaPolla, Randy J. 2016. On categorization: Stick to the facts of the languages. Linguistic Typology 20(2). 365-375.

McGregor, William B. 1994. The grammar of reported speech and thought in Gooniyandi. Australian Journal of Linguistics 14(1). 63-92.

McGregor, William B. 1997. Semiotic grammar. Oxford: Clarendon Press.

McGregor, William B. 2013. Optionality in grammar and language use. Linguistics 51(6). 1147-1204.

McGregor, William B. 2017. There's grammar and there's grammar just as there's usage and there's usage. English Text Construction 10(2). 199-232.

Michael, Lev. 2010. Rethinking quotatives, reported speech, and utterance responsibility: Implications of Nanti self-quotation. Paper given at Annual meeting of the Linguistic Society of America, 1st September 2010.

Mithun, Marianne. 2008. The extension of dependency beyond the sentence. Language 84. 69-119.

Pascual, Esther. 2014. Fictive interaction: The conversation frame in thought, language, and discourse. Amsterdam \& Philadelphia: John Benjamins.

Rijkhoff, Jan. 2016. Crosslinguistic categories in morphosyntactic typology: Problems and prospects. Linguistic Typology 20(2). 333-363.

Spronck, Stef. 2015. Reported speech in Ungarinyin: Grammar and social cognition in a language of the Kimberley region. Western Australia: Australian National University PhD thesis. 
Spronck, Stef \& Tatiana Nikitina. 2019. Reported speech forms a dedicated syntactic domain: Typological arguments and observations. Linguistic Typology.

Vandelanotte, Lieven. forthcoming. Clearer contours: The stylization of free indirect speech in nineteenth century fiction. In Peter Grund \& Terry Walker (eds.), Speech representation in the history of English. Oxford: Oxford University Press.

Verstraete, Jean-Christophe, Sarah D'Hertefelt \& An Van linden. 2012. A typology of complement insubordination in Dutch. Studies in Language 36(1). 123-153.

Wales, Katie. 2013. Alice in ego-land: The rhetoric of inanimate objects that talk. Babel: The Language Magazine 4: 35-37. 